\title{
sciendo
}

\section{Particularities of public-private partnership in the social field of the republic of Moldova}

\author{
Irina CĂLUGĂREANU \\ Academy of Economic Studies, Republic of Moldova, Chisinau \\ irinapoloz@gmail.com
}

PICBE | 411

\begin{abstract}
The evolution between the state institutions and entrepreneurship relations in developed and developing countries has proved that their constructive interaction is the most important factor for successful socio-economic development. The constantly growing gap between the needs of the population for public services, infrastructure, requirements for them, and budget constraints led to the development of partnership relations between the state and business structures. Most often, the interaction between business and state institutions is found in such areas as state property management, regional development, the real estate market, infrastructure support on technological development, transport infrastructure, utilities, medical and educational services. But to a greater degree public-private partnership, especially in the form of a concession, is applied in the field of transport and directly in road construction and we would like to emphasize that this practice is quite broad with rich experience. Interest in PPP mechanisms in other areas of activity is primarily due to the budget deficit. Without attracting the resources and potential of the institution of entrepreneurship, it is impossible to solve the task of developing a particular socially significant sphere in the context of a lack of budgetary resources. Therefore, taking into account the condition of the Republic of Moldova social sphere, more interesting is the issue of the extension of PPPs in the public sector. Therefore, the article is dedicated to features, tools and tendencies identification of public-private partnership in the social field within the Republic of Moldova.
\end{abstract}

Keywords: Republic of Moldova, public-private partnership, government, private sector, company, social infrastructure, tool, development, fund, investment, contract, concession etc.

\section{Introduction}

The experience of developed countries shows that the establishment of a public-private partnership system plays an increasingly important role in social and economic development. This model of cooperation arises, in those areas for which the state has traditionally been responsible: public facilities (transport, utilities, social infrastructure, and cultural facilities), renovation, reconstruction and maintenance of public utilities, cleaning of territories, sanitation, education, and health care. Usually, the state cannot completely abandon its presence in these sectors and is forced to maintain control over a certain property or a certain type of activity. But in order to ensure the properties maintaining and supporting its performances, financing the expenditures from the state's budget is insufficient. It requires involving additional capital, which comes through the cooperation models implementation between the state and private business.

How the implementation of public-private partnership tools will influence the social and economic development of the Republic of Moldova?? Over the years of reforms in the Republic of Moldova economy, the public sector has been significantly reduced, and the management functions of the most important social life support objects have gradually been transferred to private business. In this context, it is extremely important to move on to a viable strategic partnership with the private sector and to create a system of relations that would provide a rational combination of free competition with state management monitoring in order to serve the interests of society.

Investigation and description of this topic gave the author the opportunity to generalize certain conclusions, to answer to the main hypothese considered in the 
research that concession is the most promising mechanism of a public-private partnership in the social field and as a result, to propose to the decision-makers certain recommendations, capable of improving the activity of PPP within Republic of Moldova.

\section{Literature review}

The information resources of the article are the scientific and methodological literature in the PPP field and researches published in the Russia, the Great Britain such as Mataev T., Yescombe E. R., Farquharson E., local laws, statistic bases, data placed on the Internet by different official websites, as well as the results of author's own research. The literature has been previously addressed in a former article of the author and it built upon it.

Social infrastructure traditionally belongs to state responsibility. From a purely market position, some social infrastructure facilities are unattractive and can disappear if their assets are transferred to the private sector. Moreover, the state cannot totally transfer them to the private property, as there are socially unprotected segments of the population who cannot pay for services at a commercial cost (Yescombe, Farquharson, 2018). In practice, therefore completely logically arises so-called "semi-privatization", which often are identified as public-private partnerships (PPP). This gives reasons to consider the public-private partnerships as an intermediate model between public and private property, as well as a kind of management alternative to privatization.

The need for public-private partnership is higher in economically weaker countries. Developed countries have large budget resources to invest in the social infrastructure development. However, the investment need in social infrastructure exceeds the state budgets.

Obviously the PPP is an alternative to the privatization of state and municipal property when privatization is impossible for social or strategic reasons. The concept of public-private partnership is usually implemented in the following order (Mataev, 2014):

- developing a project in which the private sector plans, builds and operates a part of the investment object in accordance with state aims;

- financing state investments, in the form of payments for infrastructure use;

- concluding a long-term contract, which is characterized by a variety of payment methods and terms, by content and structure, that depends on the quality of services and the appearance of certain economic events, the current costs share is negotiated;

- transferring the investment object on the expiry of the contractual period in private or state ownership.

\section{Methodology}

The research methodology has a preponderant normative character and consists of theoretical principles of the concept of public-private partnership, methods and techniques of data selection (information-factual support), methods and techniques of data processing (dimension of quantitative processing), logical analysis of generalization procedures and the theory systematization).

\section{Results and discussions}

Analysis of the Republic of Moldova social infrastructure development in the past 15 years has shown that it does not provide the population with a full range of high-quality and affordable services in the field of transport, healthcare, education, housing, and utilities etc. According to the Table 1 specified data, there is a downward trend of the educational institution: in 2010-1605 units; in 2017 -1328 units and hospitals: in 2010 - 
73 units; in $2017-71$ units, the number of beds in medical institutions is 51,9 per 10,000 inhabitants. There are no changes in the housing infrastructure: the accommodation supply with such necessary parameters as gas supply and sanitation is almost at the same level. These trends are due to the extremely low level of investment in the development of these vital industries.

Table 1. Basic indexes for Republic of Moldova social infrastructure development in the 2010-2017 period

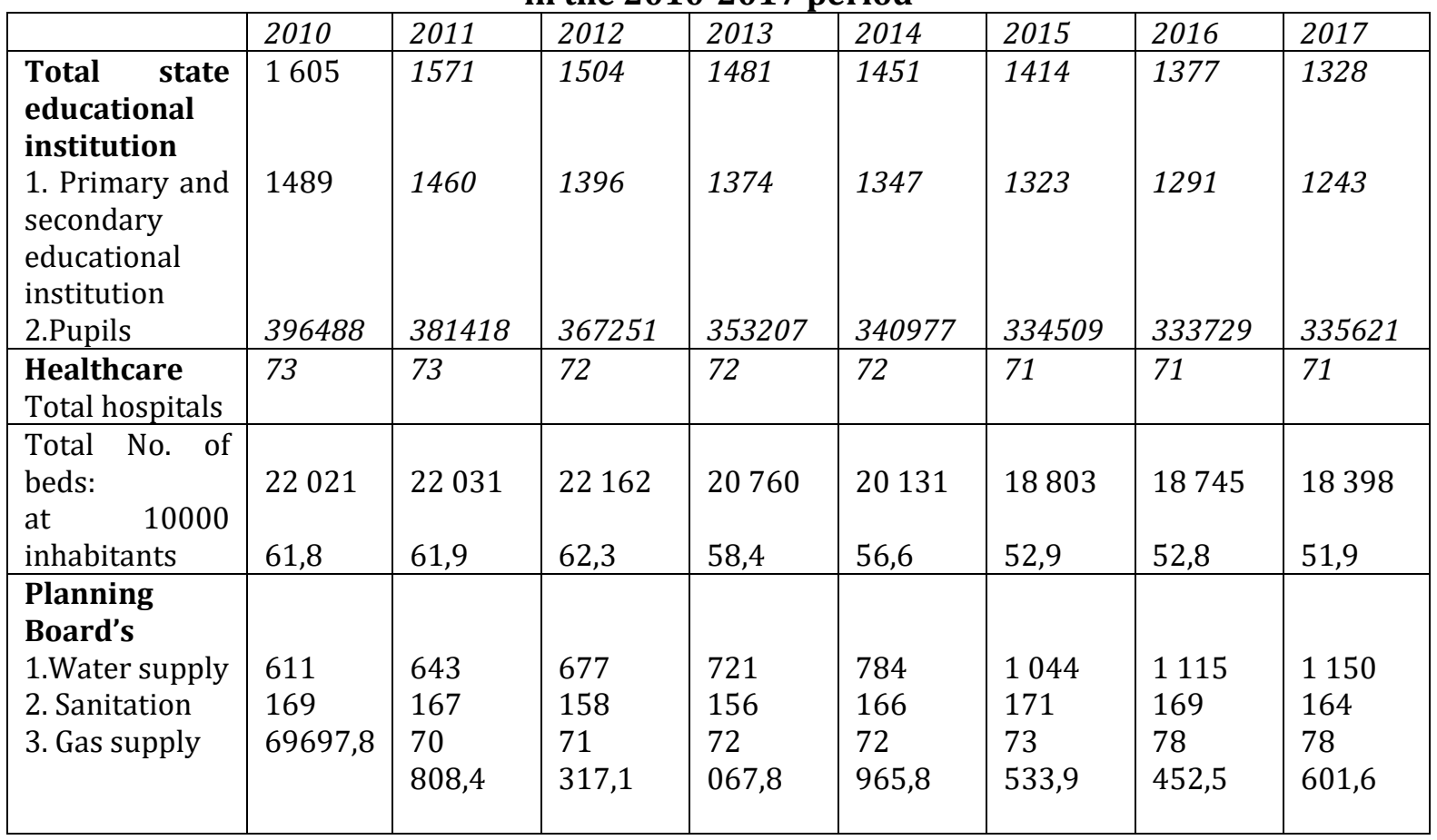

Source: National Bureau of Statistics,2018

The Republic of Moldova Water Supply and Sanitation Strategy (2014-2028), provides for the simultaneous development of water supply systems and sanitation infrastructure, but the reality is such that the aqueduct networks are developing faster than sanitation. This discrepancy is also reflected in official statistics

An essential moment for the Republic of Moldova is attenuation of the socialeconomic discrepancies insuring of life quality level increase in population from small towns and rural area. With this aim, the government needs to ameliorate the conditions for a stable increase over the entire territory of the country, including the infrastructure development and renovation (roads, water supply networks, heating systems, power nets, gas, and telecommunications). But the public expenditures over a considerable period of time are about $2-3 \%$ of the annual budget. Obviously, the budget funds are enough to maintain the infrastructure in working condition, while its expansion and modernization require additional investments. At the same time, attracting investments into social sectors while maintaining state control is a rather complicated problem, since the state cannot completely abandon its presence in these areas, but to improve the quality of provided services there is not enough budget financing. It is necessary to attract additional capital, which can come through the implementation of cooperation models between the state and private business on favorable conditions for entrepreneurs (The Republic of Moldova Practical Manual on PPP, 2015).

Furthermore, it should be considered that attracting investments in the social field is associated with a number of difficulties, because this field of the economy needs a large capital investment and has little value for money, which contradicts the Moldovan, established perception rates of return. 
This is due to the fact that the Republic of Moldova private business was formed in the process of state and municipal enterprises privatization. In connection with that, all the unrealized tasks of the government to establish an "effective segment of ownership" directly impacted the ways and methods of doing business in the Republic of Moldova. This is expressed in such deformations of the business domains such as tax evasion, payment of too low wages to employees, breaches of competitive business conditions etc. Continuation of such negative factors influence over a long period relates to the lack of economic instruments that ensuring the formation of an effective business environment.

However, in spite of all the existing difficulties, the Republic of Moldova business continues to develop and fulfill the tasks defined by it, the main one - to make a profit. Today, it can be divided into two independent areas - big business, which has a significant amount of circulating and accumulated capital (financial potential), and small/medium businesses that operate within the minimum profitability, but have significant and not yet fully realized potential, expressed in intellectual capital, management skills and practical experience of management (qualification and management capacity). These two areas of business realization represent for the state a substantial potential for the economic development, which can be used to create favorable conditions, the most important of which is the private-public partnership.

As part of this approach, it is necessary to base the state policy on business stimulation with its orientation to independent areas, where the first has a financial direction - attracting big capital for cooperation, the second should be focused on using the qualification and management potential of small and medium enterprises. Therefore, the models of PPP should be differentiated in accordance with these two directions of relations development between the state and business (Guidelines, 2003).

Recently, the relations system of business and state interaction has begun to take shape in the Republic of Moldova, taking into account the current trends in the development of big and small business entities (Law, 2008). Therefore, within the framework of solving strategic tasks of maintaining and multiplying Moldova's scientific and technological potential, the government began a gradual transfer of the science to self-sustainment with minimal funding from the public budget, but at the same time there is developed a system that supports the activities of venture innovation funds and finance high-tech and science-intensive projects with prospects for commercial use, through direct financial participation in small business projects with the aim of risks reduction.

The tendency of the private sector attraction in the exploitation of the infrastructure assets through the public-private partnership is mentioned in a series of strategic documents, adopted in the Republic of Moldova. The National Development Strategy "Moldova 2020" indicates the potential of public-private partnership exploration in the field of road infrastructure and logistics services related to transport services. The Small and Medium Enterprises Sector Development Strategy (2012-2020), indicates PPP as a priority direction for the rural infrastructure development as well as business partnership development. But only in 2018, the Republic of Moldova Ministry of Economy and Infrastructure proposed for public consultations the Draft on Venture Capital Funds Law (2018) so that small and medium-sized enterprises could benefit new forms of financing from private investors. According to the mentioned draft law, venture capital fund is defined as a fund that attracts financial resources from private investors for the purpose of investing them in innovative projects of small and medium-sized enterprises (SMEs), including those who are at an early stage of existence and have a great potential for growth and expansion. 
Venture capital investments have a high potential, driven by extended demand for SME financing. This potential remains largely untapped, although the state has proposed to develop a venture capital industry in the 1990s. So far, there are no investment offers based on venture capital in the Republic of Moldova, and this has two major consequences:

- potential investors do not have the opportunity to invest in SME business projects, which, although involve a high degree of risk, imply a higher level of investment return compared to financial investments in classical instruments;

- there are no investment platforms that would provide resources for high-risk business projects with high potential and usually are realized at start-ups founding or innovations and technology transfers implementation.

Importance of developing and adopting the regulatory framework for venture capital funds is justified by the following considerations: the limited access to finance for SMEs; insufficient funding for innovation; the limited number of financial instruments and mechanisms; poor development.

Considering the above-mentioned, the goals pursued by the government in venture capital industry development are as follows:

- supporting innovation processes, scientific and technological development;

- ensuring the attractiveness of scientifically and technically significant projects for a private venture investor;

-attracting investment in high-tech and strategic importance knowledge-intensive projects and perspective for commercial use.

Another tool for financing social infrastructure projects is Moldova Social Investment Fund (MSIF) created with the World Bank support in 1997 whose goal is sustaining the implementation by empowering poor communities and their institutions to manage their priority development needs.

The Social Investment Fund is considered to be an efficient mechanism for changing of community population's attitudes and behavior, for social activism increase, for community's solidarity spirit increase and for life quality increase in poor population and in vulnerable groups by increasing the access to improved social services.

Fostering the social partnership development at the community level and the participatory elaboration of strategic plans for community social-economic development, MSIF supports the objectives of the local public reform and contributes to capacity building of the institutions from the community, to provision of respect for participation and transparency principles, and as a result to a sustainable community development using PPP mechanisms.

The main purpose of the state in modern conditions is to create and protect market "rules of the game" for investors and "enter the game" when the markets fail. Imperative provisions of funds from the MSIF are:

- Transparency of the Fund's activities,

- Coordination of activities,

- A permanent exchange of information,

- $\quad$ Dissemination of positive experience and lessons learned during project implementation,

- Insurance of synergy and attraction of other financial sources to the MSIF beneficiary communities in order to increase the Project impact and ensure sustainable local development,

- $\quad$ Promotion of changes in social policy based on the lessons learned during the Project implementation. 
State interest in the public-private partnership is reflected in the following (Yescombe et al., 2018):

- implementation of the economic development state policy, new mechanism formation for development intensification;

- constructive interaction progress of business and government structures;

- the optimal combination of private and public investors interests, as well as enterprises that need investment attraction;

- $\quad$ significant resources mobilization for investment projects funding;

- administrative intervention mechanisms improvement in attracting and placing market investments;

- flexibility achieving in the investment resources used during the year, which allow project starting at any time, regardless of the restrictions imposed by budget processes.

Private investor's interest in the public-private partnership is reflected in: combining interests with the government can be a factor of private investment additional guarantees; investment opportunities extension is achieved in PPP due to the efficiency of capital association; investment risks reduction, due to the fact that investment objects selection are the result of expertise (companies with a transparent structure of ownership and cash flows, professional management, a clear program investments usage), additionally these companies are subject of additional control from authorized state bodies; professional management of enterprises is realized by the company managers, and are specially selected on competitive base, which makes its activities transparent and controlled by regulatory authorities, and its management is based on the optimal proportion of high profitability and balanced risk.

Therefore, the inclusion of participatory investment institutions (through venture capital investments) in the PPP circuit creates a tool where the state can invest in the priority tasks, has the opportunity to implement projects on the basis of a rational, transparent and effective partnership based on interests balance of all participants, and built by market and state financial resources strengthen.

The problem of state participation in the real sector projects is equally important from the economic policy point of view, in the attraction of the high technologies development investments and the inclusion of new modern mechanisms in the social field.

An analysis of foreign experience in using public-private partnerships has shown that the particular role of PPP is assigned to the most costly and long-paying social infrastructure projects. In the Republic of Moldova, its implementation is focused on a limited number of projects. Depending on the solved objectives in the public-private partnership, they can be divided into other separate models (Law, 2008): concession; out work/ services contracts; rental (leasing);public procurement contracts; fiduciary administration; joint ventures or civil/commercial companies with fully or partially state capital; other forms.

Table 1.2. Key elements of public-private partnership systems

\begin{tabular}{|l|l|c|c|c|c|c|}
\hline & & Services & $\begin{array}{c}\text { Private } \\
\text { Finance } \\
\text { Initiative }\end{array}$ & $\begin{array}{c}\text { Concess } \\
\text { ion }\end{array}$ & $\begin{array}{c}\text { Lease } \\
\text { Building } \\
\text { operating, } \\
\text { transfer }\end{array}$ \\
\hline Operation & Maintenance & $\mathrm{X}$ & $\mathrm{X}$ & $\mathrm{X}$ & $\mathrm{X}$ & $\mathrm{X}$ \\
\hline \multirow{3}{*}{ Funding } & $\begin{array}{l}\text { Capital investment of } \\
\text { private sector }\end{array}$ & & $\mathrm{X}$ & $\mathrm{X}$ & & $\mathrm{X}$ \\
\cline { 2 - 7 } & $\begin{array}{l}\text { Refunded on behalf of the } \\
\text { final beneficiaries }\end{array}$ & & & $\mathrm{X}$ & $\mathrm{X}$ & \\
\hline
\end{tabular}




\begin{tabular}{|l|l|c|c|c|c|c|}
\hline & $\begin{array}{l}\text { Refunded on the } \\
\text { contractual basis with the } \\
\text { state organizations }\end{array}$ & $\mathrm{X}$ & $\mathrm{X}$ & & & $\mathrm{X}$ \\
\hline Building & $\begin{array}{l}\text { Assets construction by an } \\
\text { private enterprise }\end{array}$ & & $\mathrm{X}$ & $\mathrm{X}$ & & $\mathrm{X}$ \\
\hline \multirow{3}{*}{ Property } & $\begin{array}{l}\text { State until and after } \\
\text { contract development }\end{array}$ & $\mathrm{X}$ & $\mathrm{X}$ & $\mathrm{X}$ & $\mathrm{X}$ & \\
\cline { 2 - 6 } & $\begin{array}{l}\text { Private at contract } \\
\text { development, state -after }\end{array}$ & & & $\mathrm{X}$ & & $\mathrm{X}$ \\
\hline
\end{tabular}

Each of the PPPs models has advantages and disadvantages, so the structure of the public-private partnership project must be coordinated with the priority needs of the sector and the project aims.

The author would like to mention the concession as the most common form of PPP. The concession is an agreement whereby one of the parties, called a concessionaire, delivers for a specified period to the other party, called the concessionaire, the right and obligation to operate a good, activity or public service for a fee. Its particularity is that, under the concession contract concluded, the State as a full owner of the property authorizes the concessionaire to fulfill, within a certain period of time, the functions laid down in the contract and confers on it the appropriate powers without the normal operation of the concession object it is impossible. The private partner pays a fee for using state property.

The framework of property concession in the Republic of Moldova is regulated by the Law (2018). According to the local low, a concession usually takes up to 35 years (enough time to fully amortize the major investments). Concessions are a long-term partnership that allows parties to realize strategic planning of activities. For example, in the field of social services, there are mainly used the following types of concessions:

1) Concession of major constructions, for example, a new hospital, a blood collection center, kindergarten etc;

2) Concession of public services - for existing facilities, healthcare services.

From the conclusion of a concession contract, the private enterprise gains more freedom in administrative, economic and managerial decisions, and can independently regulate many of the issues that were previously in the state's prerogative. The state, in turn, retains influence leverages on its partner.

In addition to the variety of concession types, the European Commission distinguishes (Guidelines for successful PPP, 2003): contractual nature concessions where public-private partnerships are based exclusively on contractual relationships. Consequently, the company is rewarded for its work by the public organization and/or end-users. Such concessions are governed by EU directives for public tenders; institutional concessions where public-private cooperation takes place within a particular structure. These concessions comprise all forms of public and private joint ventures.

At present, there are concluded 35 concession contracts for the sanitation service within the territorial-administrative units of the Republic of Moldova signed under the "Eco-Green" project for a maximum period of 49 years, but unfortunately, until now, no constructions have been undertaken under these PPPs (Report on the administration and privatization of state public property, 2017).

The realization of the public-private partnership through the contract for the services delivery is related to the execution of works and/or public services provided by a private partner, which concerns to execution against payment of the design, construction, 
reconstruction, complete overhaul and infrastructure elements or other public property servicing. For example in the case of public-private partnerships at the national level for health services, the Government appointed the Ministry of Health responsible for selection, negotiation and the contract concluding with a private partner. The National Health Insurance Company, during the public-private partnership period, will negotiate and conclude annual contracts for medical services provided in the framework of mandatory health insurance with the winning private partner

Public procurements are agreements that outline business transactions between companies and government entities. In the Republic of Moldova, Public Procurement Agency is a specialized administrative authority subordinated to the Ministry of Finance, which purpose is the supervision, ex-post control and inter-sectoral coordination in the public procurement field (Law, 2015). The Public Procurement Agency mission consists of the coherent implementation of state policy in the field of public procurement and the process of gradual harmonization of national legislation with Community law. The value of the public procurement contracts registered by the Public Procurement Agency in 2017 amounted to 8605 million lei, which represents about 5,72\% of the public procurement in GDP share (Public Procurement Agency Report, 2017).

Other models of public-private partnership are rental/lease-purchase relationships that occur with the placing into possession the state property to the private sector on a contractual base: buildings, production equipment etc. The payment for the state property usage is the royalty that is paid to the state (Government Decision, 1997). For example, the basic rate for the annual rent of one $\mathrm{m} 2$ of public property space in Chisinau municipality in 2018 is about 17 Euro, in villages the rent price of one $\mathrm{m} 2$ reaches 2.5 Euro according to the state budget of 2018.

A widespread model of public-private partnerships are joint ventures or civil/commercial companies with fully or partially state ownership, which can also be achieved by associating the public and private partner either on the basis of a contract without formation of any legal entity, or by a joint venture creation (limited liability company or joint stock company) based on joint (public-private) capital. Public-private partnerships in the form of a legal entity may be initiated by the public partner through selling a part of the company's share capital. The participation of the private sector in the share capital of a company may include corporatization and the creation of joint ventures. The level of private sector freedom in taking administrative and economic decisions is determined by its part in the share capital.

The Register of Public Heritage contains references for 90 state-owned companies, out of which in 71 companies the state has over 30 percent share capital, including 22 companies with fully state-owned capital and 46 major state-owned capital. The share capital of commercial companies amounts to 4913,03 million lei, of which state property - 3722,47 million lei or $75,76 \%$. Although of the total number of state-owned companies managed by the central public authorities, 24 state-owned enterprises and 37 commercial companies are subject to liquidation or insolvency procedure (Report on the administration and privatization of state public property, 2017).

An eloquent example of a viable partnership in the Republic of Moldova is the establishment of the MoldFarm Inc, with a full state share being shareholder the Public Property Agency. "MoldFarm" Inc. that has rights to carry out the following activities in the pharmaceutical field: the acquisition, import, storage, sale of medical and medical devices, perfumery and cosmetics, technical items and medical optics (Government Decision, , 2016). 
Till present, public authorities of the Republic of Moldova reported 77 PPP contracts and concessions (out of which 12 are terminated), including 9 contracts at the central level and 56 at the local level as follows (Report on the administration and privatization of state public property, 2017):

1) Public-private partnership projects initiated in the healthcare domain;

2) Public-private partnership projects initiated in the social construction for budgetary sector employees;

3) Public-private partnerships for public services modernizing;

4) Public-private partnerships for hydrocarbon exploration;

5) Concession contracts for localities' sanitation services.

As we can see the particularities of state regulation on business partnership are determined by the general expansion of agreement relations with private sector enterprises, non-profit and public organizations in areas that were previously the prerogative of the public sector. Such a partnership requires an adequate improvement of the contractual tools, including guarantees of compliance by the parties with their obligations, risk sharing, and income distribution mechanisms.

\section{Conclusion}

Generalizing the features and tendencies of public-private partnership in the social field within the Republic of Moldova above exposed, we come to the conclusion that today, the main directions of state policy in developing PPPs are concentrated in the implementation of several mechanisms, including: the development of technology parks, concession agreements, promotion of venture investment through the creation of a venture capital company, formation of financial development institutions, and others. The implementation of PPP's schemes is able to ensure, firstly, the possibility of realization, in the shortest possible time, socially significant projects in the most non-attractive areas for traditional forms of private financing. Secondly, to improve the efficiency of projects through the participation of private business, which, in contrast to state institutions, could solve production and management tasks in the market conditions more effectively. Third, to reduce the burden on the budget by attracting private funds and shifting part of the costs to users, involving the best managerial staff, equipment and technologies, and improving the service quality for end-consumers; creating conditions to state bodies in concentrating the attention on the administrative functions, as well as helping to reduce risks by distributing them between private partners and the authorities.

However the development of public-private partnership tools involves, as well, expanding of leasing and concession mechanisms usage and mixed financing practice of projects and social programs investment, which makes the forward-looking widespread attraction of private capital to meet the modernizing social infrastructure challenges. According to EU practices, the author considers concession as the most promising mechanism of a public-private partnership in the social field of the Republic of Moldova, because of its efficiency at various stages of the investment process and its successfully combination with the state control. Also, key policy measures in the social field should focus on creating a self-regulating model, the development of which will be conditioned by intense interactions between the public and the private sector. The implementation of PPP mechanisms at the national level will accelerate the development of the social services market and will also contribute to the formation of an efficient competitive environment, the optimal management of financial resources, the improvement of quality and the provided number of services increase. In addition, the development of publicprivate partnerships will create a favorable investment climate and accelerate the incorporation of state guarantees. 


\section{References}

Government Decision (1997). Referring to the mode of rent the public goods and the amount of rent No. $692 . \quad$ Retrieved from http://lex.justice.md/document_rom.php?id=873A7CFB:0D1B9A24.

Government Decision (2016). Referring to creation of "MoldFarm" S.A. no. 1336. Retrieved from http://lex.justice.md/md/367965/.

Guidelines (2003). A successful public - private partnerships. Retrieved from https://ec.europa.eu/regional_policy/sources/docgener/guides/ppp_en.pdf

Draft of Law (2018). Venture Capital Funds Law. Retrieved from http://particip.gov.md/proiectview.php?l=ro\&idd=5023.

Law (2018). Referring to concessions and service concessions building 121/2018. Retrieved from http://lex.justice.md/md/376821\%20/.

Law (2015). Public procurements 131/2015. Retrieved from http://lex.justice.md/md/360122/.

Law (2008). Public-private partnership 179/2008. Retrieved from http://lex.justice.md/md/328990/

Mataev T. (2014). Classification of forms and models of public-private partnerships. Retrieved from https://articlekz.com/article/15400

Public Procurement Agency (2017). Annual Report. Retrieved from https://tender.gov.md/ro/documente/rapoarte-de-activitate

The Moldova Social Investment Fund (2018). Retrieved from https://fism.gov.md/

The National Development Strategy "Moldova 2020". Retrieved from http://lex.justice.md/index.php?action=view\&view=doc\&id=345635

The National Bureau of Statistics (2018). Retrieved from http://statistica.gov.md/

The Republic of Moldova practical manual on PPP and concessions 2015. Retrieved from https://app.gov.md/ro/advanced-page-type/manual-ppp

The Republic of Moldova Report on the administration and privatization of state public property, 2017. Retrieved from https://app.gov.md

The Republic of Moldova Water Supply and Sanitation Strategy 2014-2028. Retrieved from http://lex.justice.md/md/352311/

The Small and Medium Enterprises Sector Development Strategy 2012-2020. Retrieved from

http://lex.justice.md/viewdoc.php?action=view\&view=doc\&id=344806\&lang=1

Yescombe E. R., Farquharson E. (2018). Public-Private Partnerships for Infrastructure 2nd Edition. UK: Butterworth-Heinemann2018. 